\title{
Aberrant Mechanical Efficiency during Exercise Relates to Metabolic Health and Exercise Intolerance in Adolescents with Obesity
}

\author{
Wouter M. A. Franssen ${ }^{1,2} \mathbb{D}$, Guy Massa ${ }^{2,3}$, Bert O. Eijnde ${ }^{2}$, Paul Dendale ${ }^{2,4}$, Dominique Hansen ${ }^{1,2,4,+}$ \\ and Kenneth Verboven $1,2, *,+\mathbb{D}$ \\ 1 REVAL - Rehabilitation Research Center, Faculty of Rehabilitation Sciences, Hasselt University, \\ 3590 Diepenbeek, Belgium; wouter.franssen@uhasselt.be (W.M.A.F.); dominique.hansen@uhasselt.be (D.H.) \\ 2 BIOMED-Biomedical Research Center, Faculty of Medicine and Life Sciences, Hasselt University, \\ 3590 Diepenbeek, Belgium; guy.massa@jessazh.be (G.M.); bert.opteijnde@uhasselt.be (B.O.E.); \\ paul.dendale@jessazh.be (P.D.) \\ 3 Department of Pediatrics, Jessa Hospital, 3500 Hasselt, Belgium \\ 4 Heart Centre Hasselt, Jessa Hospital, 3500 Hasselt, Belgium \\ * Correspondence: kenneth.verboven@uhasselt.be; Tel.: +32-(0)11-28-69-49 \\ + These authors contributed equally as last author.
}

check for

updates

Citation: Franssen, W.M.A.;

Massa, G.; O. Eijnde, B.; Dendale, P.;

Hansen, D.; Verboven, K. Aberrant

Mechanical Efficiency during Exercise

Relates to Metabolic Health and

Exercise Intolerance in Adolescents

with Obesity. Int. J. Environ. Res.

Public Health 2021, 18, 10578. https://

doi.org/10.3390/ijerph182010578

Academic Editor: Ann M. Swartz

Received: 4 August 2021

Accepted: 5 October 2021

Published: 9 October 2021

Publisher's Note: MDPI stays neutral with regard to jurisdictional claims in published maps and institutional affiliations.

Copyright: (c) 2021 by the authors. Licensee MDPI, Basel, Switzerland. This article is an open access article distributed under the terms and conditions of the Creative Commons Attribution (CC BY) license (https:// creativecommons.org/licenses/by/ $4.0 /)$.

\begin{abstract}
Background. Mechanical efficiency (ME) might be an important parameter evaluating cardiometabolic health and the effectiveness of physical activity interventions in individuals with obesity. However, whether these cardiometabolic risk factors may relate to ME in adolescents with obesity is not known yet. Therefore, this study aims to compare the mechanical efficiency during maximal exercise testing between adolescents with obesity and lean adolescents, and to examine associations with exercise tolerance and metabolic health. Methods. Twenty-nine adolescents with obesity (BMI SDS: $2.11 \pm 0.32$, age: $13.4 \pm 1.1$ years, male/female: 15/14) and 29 lean (BMI SDS: $-0.16 \pm 0.84$, age: $14.0 \pm 1.5$ years, male/female: $16 / 13$ ) adolescents performed a maximal cardiopulmonary exercise test from which the net mechanical efficiency $\left(\mathrm{ME}_{\mathrm{net}}\right)$ and substrate oxidation (carbohydrates and lipids) were calculated. Indicators for peak performance were collected. Biochemistry (lipid profile, glycaemic control, inflammation, leptin) was studied in fasted blood samples. Regression analyses were applied to examine relations between $\mathrm{ME}_{\text {net }}$ and exercise tolerance or blood variables in the total group. Results. Peak work rate $\left(\mathrm{WR}_{\text {peak }}\right)$, oxygen uptake $\left(\dot{\mathrm{VO}}_{2 \text { peak }}\right) / \mathrm{WR}_{\text {peak }}$ $\mathrm{ME}$, and $\mathrm{ME}_{\text {net }}$ were significantly lower $(p<0.05)$ in adolescents with obesity compared to their lean counterparts $(p<0.05)$. Furthermore, a reduced $\mathrm{ME}_{\text {net }}$ was independently related to a lower $\mathrm{WR}_{\text {peak }}(\mathrm{SC} \beta=2.447 ; p<0.001$ ) and elevated carbohydrate oxidation during exercise (SC $\beta=-0.497$; $p<0.001$ ), as well as to elevated blood low-density lipoprotein cholesterol (SC $\beta=-0.275 ; p=0.034$ ) and fasting glucose (SC $\beta=-0.256 ; p=0.049$ ) concentration. Conclusion. In adolescents with obesity, the mechanical efficiency is lowered during exercise and this relates to exercise intolerance and a worse metabolic health.
\end{abstract}

Keywords: exercise tolerance; mechanical efficiency; physical fitness; metabolic risk factors; adolescents

\section{Introduction}

The prevalence of obesity has increased considerably among adolescents over the past decades and has become one of the most significant health concerns worldwide [1]. Recent data indicate that the number of children and adolescents with obesity worldwide has increased up to 62 million in 2016 [1]. Obesity contributes to morphological and functional anomalies of adipocytes and adipose tissue, resulting in a pathophysiological process termed adiposopathy [2]. Due to adiposopathy, adolescents with obesity are at significantly greater risk to develop cardiovascular, metabolic, hepatic, respiratory, and orthopaedic disorders, compared to their non-obese peers [3]. As a result of these complications, 
childhood obesity alone results in a major economic burden, even if normalization of weight status is achieved during adulthood [4].

Cardiopulmonary exercise testing (CPET) provides valuable diagnostic and prognostic information of the integrative responses of the cardiovascular, pulmonary, and muscular system. During CPET, a lower peak cycling power output, oxygen uptake, and heart rate response to exercise are often observed in adolescents with obesity [5-8]. Next to these classical CPET parameters, mechanical efficiency (ME) has been examined as an important parameter evaluating muscular function and its relation to cardiometabolic health, as well as the effectiveness of physical activity interventions in adults with obesity $[9,10]$. ME refers to the ability of an individual to transfer the total metabolic energy costs into external work [11]. It has previously been shown that ME is reduced during steady state (submaximal) exercise in adults with obesity and, therefore, this population is limited in terms of physical activity, subsequently leading to a vicious cycle of physical inactivity and worse cardiometabolic health [12]. Although ME has been investigated in children and adolescents with obesity during submaximal exercise $[7,8]$ it remains to be determined whether these differences could be observed during CPET, which is often performed as a comprehensive, time-efficient diagnostic test in clinical practice. However, for maximal exercise testing, current ME literature is controversial based on discrepancies in maximal effort indicators (e.g. peak heart rate and peak respiratory exchange ratio) [7]. In addition, these studies did not evaluate metabolic health which may be associated with ME. Of interest, physical activity intervention induced improvements in both ME and cardiometabolic health in sedentary obese adults [9], although no direct associations have been determined in current literature, especially in obese adolescents. Previous studies have shown that exercise capacity is negatively associated with metabolic risk factors such as insulin resistance in (adolescent) patients with obesity $[13,14]$. The relation between metabolic disease risk and cardiorespiratory fitness becomes even stronger in children with elevated adipose tissue mass [15]. Hence, it may be anticipated that these metabolic risk factors may relate to mechanical inefficiency.

Therefore, the current study aimed (1) to compare ME during conventional CPET between adolescents with obesity and lean adolescents; and (2) to examine the associations between $\mathrm{ME}$ and determinants of metabolic health or exercise tolerance. It was hypothesized that ME is diminished during CPET, and that these alterations are associated with deviations in specific metabolic risk factors or exercise tolerance. If this hypothesis is confirmed, ME during CPET might be of clinical importance in adolescents with obesity as this can be a novel indicator for the presence or possible development of cardiometabolic complications among obese adolescents.

\section{Materials and Methods}

The study was carried out according to an observational, cross-sectional design, and was performed at the Jessa Hospital (Hasselt, Belgium) between November 2016 and July 2017, as described previously [5]. From midnight prior to a one-day hospitalization, all subjects refrained from consuming food, with the exception of water ad libitum, to prevent short-term metabolic effects on outcome parameters. After registration of general characteristics, such as anthropometry, body composition, Tanner stage, and blood pressure, venous blood samples were collected (in a fasted state) to examine participants' cardiometabolic health. After this, one hour prior to CPET, a standardized meal (total energy: $296 \mathrm{kcal}$; composed of $3 \mathrm{~g}$ fats, $56 \mathrm{~g}$ carbohydrates and $9 \mathrm{~g}$ proteins) was consumed.

\subsection{Participants}

Adolescents with obesity were recruited from the pediatric clinic of Jessa Hospital (Hasselt, Belgium) and lean adolescents were recruited by means of paper advertisements at Jessa Hospital and Hasselt University (Hasselt, Belgium). Participants were between 11 and 17 years of age and free from any known chronic cardiovascular, renal, pulmonary, or orthopedic disease. Twenty-nine adolescents with obesity (BMI SDS: $2.11 \pm 0.32$, age: 
$13.4 \pm 1.1$ years, male/female: $15 / 14$ ) and 29 lean adolescents (BMI SDS: $-0.16 \pm 0.84$, age: $14.0 \pm 1.5$ years, male/female: $16 / 13$ ) were included in this study based on the International Obesity Task Force criteria and body fat percentage ( $>95^{\text {th }}$ percentile) $[16,17]$. Body weight, BMI, BMI-SDS, waist circumference, hip circumference, waist-to-hip ratio, and the percentage of body fat $(p<0.001)$ were higher in subjects with obesity (Table 1 and Table S1). Both systolic $(p<0.001)$ and diastolic $(p=0.006)$ BP were increased in adolescents with obesity, compared to lean adolescents. All participants and their parents or legal guardians received oral and written information about the aim and protocol of the study and gave their written informed consent prior to participation. The study protocol was approved by the medical ethical committee of Jessa Hospital and Hasselt University (no. B243201214935) and was executed according to the Declaration of Helsinki (2013). The present study is registered at ClinicalTrials.gov with number NCT03516721.

Table 1. Subject characteristics of obese and lean individuals.

\begin{tabular}{cccc}
\hline General Features & Obese $(\boldsymbol{n = 2 9 )}$ & Lean $(\boldsymbol{n}=\mathbf{2 9})$ & $p$-Value \\
\hline Age (years) & $013.4 \pm 1.10$ & $014.0 \pm 1.50$ & 0.078 \\
Sex & 15 & & 0.792 \\
Male $(n)$ & 14 & 16 & $<0.001$ \\
Female $(n)$ & $088.0 \pm 15.3$ & $054.7 \pm 10.8$ & 0.949 \\
Body weight $(\mathrm{kg})$ & $166.7 \pm 8.70$ & $166.8 \pm 8.90$ & 0.595 \\
Body height $(\mathrm{cm})$ & $0.82 \pm 0.99$ & $0.68 \pm 1.00$ & $<0.001$ \\
Body height-SDS & $031.6 \pm 4.20$ & $019.5 \pm 2.40$ & $<0.001$ \\
BMI (kg/m $\left.{ }^{2}\right)$ & $2.11 \pm 0.32$ & $-0.16 \pm 0.84$ & $<0.001$ \\
BMI-SDS & $103.0 \pm 12.8$ & $067.4 \pm 6.20$ & $<0.001$ \\
Waist circumference (cm) & $104.1 \pm 8.20$ & $078.7 \pm 8.30$ & $<0.001$ \\
Hip circumference $(\mathrm{cm})$ & $00.99 \pm 0.07$ & $00.86 \pm 0.11$ & $<0.001$ \\
Waist-to-hip ratio & $047.6 \pm 10.7$ & $18.0 \pm 5.7$ & $<0.001$ \\
Body fat $(\%)$ & $42.7 \pm 15.5$ & $10.1 \pm 4.3$ & 0.766 \\
Body fat (kg) & $45.3 \pm 8.7$ & $44.6 \pm 8.4$ & $<0.001$ \\
Fat-free mass $(\mathrm{kg})$ & $125 \pm 11$ & $114 \pm 10$ & 0.006 \\
Systolic BP $(\mathrm{mmHg})$ & $76 \pm 10$ & $70 \pm 7$ & $<0.001$ \\
Diastolic BP $(\mathrm{mmHg})$ & $92 \pm 8$ & $85 \pm 7$ & 0.271 \\
Mean arterial pressure & & &
\end{tabular}

Data are expressed as mean \pm SD. Abbreviations: SDS: standard deviation score, BMI: body mass index, BP: blood pressure. Comparisons between groups were tested using the chi-square test for categorical variables. Comparisons between groups were performed using the independent-samples t-test or Mann-Whitney U test for continuous variables.

\subsection{Auxological Parameters and Blood Pressure}

Body height was measured to the nearest $0.1 \mathrm{~cm}$ using a wall-mounted Harpenden stadiometer (ICD 250 DW, De Grood Metaaltechniek, Nijmegen, The Netherlands), with participants barefoot. Body weight (in underwear) was determined using a digital-balanced weighing scale to the nearest $0.1 \mathrm{~kg}$ (Seca 770, Hamburg, Germany). Body mass index (BMI) was calculated from weight and height measurements (weight $/$ height $^{2}$ ). The body height and BMI standard deviation scores (SDS) were calculated, as described by Cole et al., as: body height-SDS $=\left[(\text { body height } / \mathrm{M})^{\mathrm{L}}-1\right] /[\mathrm{L} * \mathrm{~S}]$ and BMI-SDS $=\left[(\mathrm{BMI} / \mathrm{M})^{\mathrm{L}}-\right.$ $1] /[\mathrm{L} \times \mathrm{S}][16,18]$. Waist and hip circumferences were measured to the nearest $0.1 \mathrm{~cm}$ using a flexible metric measuring tape with participants barefoot (in underwear) in standing position. Waist circumference was measured at the midpoint between the lower rib margin and the top of the iliac crest. Hip circumference was measured at the widest circumference of the hip at the level of the greater trochanter. Waist-to-hip ratio was calculated by dividing 
waist circumference $(\mathrm{cm})$ by hip circumference $(\mathrm{cm})$. Body composition was evaluated using skinfold measurements. The thickness of the skinfolds were measured in triplicate at the left side of the body to the nearest $0.1 \mathrm{~mm}$ using an Harpenden skinfold caliper (Baty, West Sussex, UK), at the following sites: triceps, halfway between the acromion process and the olecranon process; biceps, at the same level as the triceps skinfold, directly above the center of the cubital fossa; subscapular, about $2 \mathrm{~cm}$ below the tip of the scapula, at an angle of $45^{\circ}$ to the lateral side of the body; and suprailiac, about $2 \mathrm{~cm}$ above the iliac crest, in the axillary line [19]. The mean value of the triplicate measurements was used in the analysis. Skinfold measurements were performed by the same observer. The percentage of body fat was calculated using the equation reported by Slaughter et al. [20]. Pubertal status was assessed using Tanner's scale according to observation by a pediatrician or the adolescents' own opinion based on a figure. Blood pressure (BP, $\mathrm{mm} \mathrm{Hg}$ ) was measured in supine position using an electronic sphygmomanometer (Omron ${ }^{\circledR}$, Omron Healthcare, IL, USA) after a resting period of five minutes. Mean arterial pressure (MAP, $\mathrm{mm} \mathrm{Hg}$ ) was calculated as $\mathrm{MAP}=$ systolic $\mathrm{BP}+(2 *$ diastolic $\mathrm{BP}) / 3$.

\subsection{Biochemical Analyses}

After antecubital catheter placement, venous blood samples were taken for the measurement of biochemical blood parameters. Plasma glucose $(\mathrm{mg} / \mathrm{dL})$, uric acid $(\mathrm{mg} / \mathrm{dL})$, lipid profile (blood total cholesterol (mg/dL), high-density lipoprotein (HDL, mg/dL) cholesterol, low-density lipoprotein (LDL, $\mathrm{mg} / \mathrm{dL}$ ) cholesterol and triglyceride concentration $[\mathrm{mg} / \mathrm{dL}])$, c-reactive protein $(\mathrm{CRP}, \mathrm{mg} / \mathrm{dL})$ and serum insulin concentrations $(\mathrm{mU} / \mathrm{L})$ were automatically assessed using Roche Cobas 8000 (Roche Diagnostics International Ltd, Rotkreuz, Switzerland). Blood glycated haemoglobin (HbA1c, \%) concentration was measured using ion exchange chromatography (Menarini HA- $8180 \mathrm{HbA1c}$ auto-analyser, Menarini Diagnostics, Diegem, Belgium). Serum leptin concentration ( $\mu \mathrm{g} / \mathrm{l})$ was measured using radioimmunoassay (RIA; Linco Research Inc., Saint Louis, MI, USA). Whole-body insulin resistance was estimated using the homeostatic model assessment for insulin resistance (HOMA-IR) and calculated as fasting glucose concentration $(\mathrm{mg} / \mathrm{dL}){ }^{*}$ fasting insulin concentration $(\mu \mathrm{U} / \mathrm{mL}) / 405[21]$.

\subsection{Cardiopulmonary Exercise Testing (CPET)}

CPET was performed up to volitional exhaustion using an electronically braked cycle ergometer (eBike, GE Medical systems, Milwaukee, WI, USA), controlled by the Cardiosoft electrocardiography software (Cardiosoft 6.6, GE Medical systems, Milwaukee, WI, USA). At the beginning of each test day, a gas and volume calibration was performed according to manufacturer's instructions. During the test, environmental temperature was kept stable at $19-21^{\circ} \mathrm{C}$. The exercise test (ramp protocol) included a one-minute pre-exercise resting period, a one-minute warm-up cycling (unloaded exercise) period, and an incremental exercise cycling phase with an initial work rate of $40 \mathrm{~W}$ with an increasing work rate of $20 \mathrm{~W}$ per minute until exhaustion or other symptoms limiting the test. During warm-up cycling and incremental exercise, a cycling frequency of 60 to 70 revolutions per minute $(\mathrm{rpm})$ had to be maintained. The test was ended when the individuals failed to maintain a pedal frequency of at least $60 \mathrm{rpm}$. All subjects were verbally encouraged during exercise testing to achieve maximal effort, based on a respiratory gas exchange ratio (RER) of $\geq 1.10$, and subjective opinion of an experienced tester who confirmed whether a maximal exercise test was executed, based on subjective features, such as dyspnea, sweating, facial flushing, clear unwillingness to continue, and a sustained drop in the participants pedaling frequency despite verbal encouragement, as described by Bongers et al. [22]. Due to the potential presence of chronotropic incompetence in adolescents with obesity, the heart rate at peak exercise $\left(\mathrm{HR}_{\text {peak }}, \mathrm{bpm}\right)$ was not used as a criterion for maximal exercise effort [23]. After cessation of exercise, work rate was set at $45 \mathrm{~W}$ at which subjects cycled during two minutes for active recovery with a cycling frequency of $50 \mathrm{rpm}$. 
Continuous pulmonary gas exchange analysis (Jaeger MasterScreen CPX Metabolic Cart, CareFusion Germany GmbH, Hoechberg, Germany) was used to measure oxygen uptake $\left(\dot{\mathrm{VO}}_{2}, \mathrm{~mL} / \mathrm{min}\right)$, carbon dioxide output $\left(\dot{\mathrm{V}} \mathrm{CO}_{2}, \mathrm{~mL} / \mathrm{min}\right)$, minute ventilation ( $\dot{\mathrm{V}}$, $1 / \mathrm{min})$, equivalents for oxygen uptake $\left(\dot{\mathrm{VE}} / \dot{\mathrm{VO}}_{2}\right)$ and carbon dioxide output $\left(\dot{\mathrm{VE}} / \dot{\mathrm{V} C O}{ }_{2}\right)$, tidal volume ( $\mathrm{Vt}, \mathrm{l})$, breathing frequency ( $\mathrm{f}$, breaths per minute) and RER, and collected breath-by-breath with averaging every ten seconds. First ventilatory threshold (VT1) was determined using the $\mathrm{V}$-slope method and was expressed in $\mathrm{mL} / \mathrm{min} \mathrm{VO}_{2}$ [24]. The second ventilatory threshold (VT2) was determined, using the $\dot{\mathrm{VE}}$ vs. $\dot{\mathrm{V}} \mathrm{CO}_{2}$ plot, on the point where $\dot{\mathrm{VE}}$ increases out of proportion to $\dot{\mathrm{V} C O}{ }_{2}$ and expressed in $\mathrm{mL} / \mathrm{min} \dot{\mathrm{VO}}_{2}$ [25]. In addition, peak work rate $\left(\mathrm{WR}_{\text {peak }}\right.$, Watt) was reported. The mechanical efficiency (ME) of cycling was determined, as described by Garby et al., and calculated as WR (Watt)/total energy consumption $(\mathrm{mL} / \mathrm{min})$, whereby the energy expenditure was calculated as $\left[(4.94 \times \mathrm{RER}+16.04) \times\left(\mathrm{VO}_{2}\right.\right.$, in $\left.\left.\mathrm{mL} / \mathrm{min}\right) / 60\right] \times 100$ [26]. The net ME $\left(\mathrm{ME}_{\text {net }}\right)$ was calculated from the ratio of work performed to the rate of energy expenditure above rest as described by Lafortuna et al. [12]. Using a 12-lead ECG device (KISS ${ }^{\text {TM }}$ Multilead, GE Medical systems, Freiburg, Germany) HR was monitored and averaged every ten seconds. Substrate oxidation (g/min) was calculated based on $\dot{\mathrm{VO}}_{2}$ and $\dot{\mathrm{V}} \mathrm{CO}_{2}$, as described by Frayn et al. [27].

\subsection{Statistical Analysis}

Statistical analysis was performed by IBM SPSS ${ }^{\circledR}$ version 24.0 (IBM SPSS Statistics for Windows, Chicago, IL, USA). Data were expressed as mean \pm standard deviation (SD). Shapiro-Wilk tests were used to test normality of the data $(p<0.05)$. Comparisons between groups were tested using the chi-square test for categorical variables. Differences between continuous variables were assessed using independent sample T-tests for normally distributed data and Mann-Whitney U-tests for abnormally distributed data. A two-way repeated-measures ANOVA was used to assess whether there were differences in ME between adolescent with obesity and lean adolescents: an interaction effect was evaluated, where group (adolescents with obesity vs. lean adolescents) was a between-subjects factor, and time (percentage of $\dot{\mathrm{VO}}_{2 \text { peak }}$ ) was a within-subjects factor. A post-hoc analysis (Bonferroni post-hoc comparison test) was performed when the between-subjects factor was statistically significant. Multivariate linear regression analysis was applied to examine relations between altered ME and metabolic health parameters or CPET parameters in both groups. In these regression analyses, corrections for age, sex, and the Tanner stage were made. Variables with a beta-coefficient $<0.1$ were left out of consideration. A $p$-value $<0.05$ (2-tailed) was considered statistically significant.

The sample size calculation was performed using GPower v. 3.1 (Düsseldorf, Germany) and based on a previous study from Marinus et al. that showed a reduced $W R_{\text {peak }}$ (effect size d: 0.93) in adolescents with obesity [28]. Based on a statistical power $>0.8$ and a two-sided alpha of 0.05 , it was calculated that a sample size of at least 26 individuals with obesity and 26 healthy controls had to be included in the present study. Taking into account a drop-out rate of $10 \%$, the number of participants to include in this study was at least 29 lean and 29 adolescents with obesity, resulting in a final sample size of 58 subjects.

\section{Results}

\subsection{Biochemical Parameters}

Blood HDL cholesterol concentration was lower $(p<0.05)$, whereas blood uric acid, CRP, LDL cholesterol, triglycerides, triglyceride-to-HDL cholesterol ratio, glucose, insulin, and leptin concentrations were all higher $(p<0.05)$ in adolescents with obesity (Table 2 and Table S2). Whole-body insulin resistance reflected by HOMA-IR was elevated $(p<0.001)$ in adolescents with obesity compared to lean adolescents. 
Table 2. Biochemical and hormonal parameters in obese and lean adolescents.

\begin{tabular}{|c|c|c|c|}
\hline & Obese $(n=29)$ & Lean $(n=29)$ & $p$-Value \\
\hline \multicolumn{4}{|l|}{ Cardiovascular risk factors } \\
\hline C-reactive protein (mg/l) & $04.2 \pm 6.9$ & $00.3 \pm 0.8$ & $<0.001$ \\
\hline Total cholesterol (mg/dL) & $158 \pm 33$ & $150 \pm 24$ & 0.308 \\
\hline LDL cholesterol (mg/dL) & $094 \pm 27$ & $075 \pm 22$ & 0.004 \\
\hline HDL cholesterol (mg/dL) & $045 \pm 11$ & $061 \pm 12$ & $<0.001$ \\
\hline Triglycerides (mg/dL) & $102 \pm 58$ & $071 \pm 35$ & 0.017 \\
\hline Triglyceride-to-HDL cholesterol ratio & $2.4 \pm 1.4$ & $1.2 \pm 0.8$ & $<0.001$ \\
\hline Uric acid $(\mathrm{mg} / \mathrm{dL})$ & $05.7 \pm 0.8$ & $05.1 \pm 1.1$ & 0.036 \\
\hline \multicolumn{4}{|l|}{ Glycaemic control } \\
\hline Fasting glucose (mg/dL) & $89 \pm 6$ & $85 \pm 6$ & 0.031 \\
\hline Fasting insulin $(\mathrm{mU} / \mathrm{l})$ & $026 \pm 16$ & $10 \pm 5$ & $<0.001$ \\
\hline Glycated haemoglobin (\%) & $05.3 \pm 0.3$ & $05.2 \pm 0.2$ & 0.064 \\
\hline HOMA-IR & $05.7 \pm 3.7$ & $02.1 \pm 1.2$ & $<0.001$ \\
\hline \multicolumn{4}{|l|}{ Endocrinology } \\
\hline Leptin $(\mu \mathrm{g} / \mathrm{L})$ & $046.9 \pm 22.0$ & $08.7 \pm 6.3$ & $<0.001$ \\
\hline
\end{tabular}

Data are expressed as mean \pm SD. Abbreviations: LDL: low-density lipoprotein, HDL: High-density lipoprotein, HOMA-IR: Homeostatic Model Assessment of Insulin Resistance. Comparisons between two groups were performed using the independent-samples t-test or Mann-Whitney U test.

\subsection{Exercise Tolerance and Mechanical Efficiency}

At rest, $\mathrm{VO}_{2 \text { rest }}(\mathrm{mL} / \mathrm{min}: p=0.036), \dot{\mathrm{VCO}_{2 \text { rest }}}(p=0.017), \mathrm{HR}_{\text {rest }}(p<0.001)$, and carbohydrate oxidation $p<0.001$ ) were found to significantly increase in adolescents with obesity compared to lean adolescents. In addition, a lower $\mathrm{VO}_{2 \text { rest }}(\mathrm{mL} / \mathrm{min} / \mathrm{kg}: p<0.001)$ was found in adolescents with obesity. Furthermore, a lower lipid oxidation $(p=0.033)$ was observed in adolescents with obesity (Table S3).

At peak exercise, a significantly reduced $\mathrm{VO}_{2 \text { peak }}(\mathrm{mL} / \mathrm{min} / \mathrm{kg}: p<0.001), \mathrm{WR}_{\text {peak }}$ $(p=0.010), \dot{\mathrm{VO}}_{2 \text { peak }} / \mathrm{WR}_{\text {peak }}, \mathrm{ME}(p<0.001)$, and $\mathrm{ME}_{\text {net }}(p=0.005)$ were found in adolescents with obesity (Table 3 ). During CPET, $\mathrm{VO}_{2 \text { peak }} / \mathrm{WR}_{\text {peak }}$ (Figure 1 and Figure S1) was significantly higher (within-subjects: $p<0.001$; between between-subjects: $p=0.001$ ) and ME (Figure 2a and Figure S2) was significantly lower (within-subjects: $p<0.001$; between between-subjects: $p<0.001$ ) in adolescents with obesity, irrespective of gender. In addition, $\mathrm{ME}_{\text {net }}$ (Figure 2b) was significantly reduced (within-subjects: $p<0.001$; between betweensubjects: $p=0.048$ ) in adolescents with obesity at low-, moderate-, and vigorous-intense exercise. In addition, similar results were found at VT1 and VT2 (Table S3). However, no interaction effects (adolescents with obesity vs. lean adolescents as a between-subjects factor and percentage of $\dot{\mathrm{VO}}_{2 \text { peak }}$ as a within-subjects factor) were found. No other CPET parameters differed between groups $(p>0.05)$.

Table 3. Cardiopulmonary function during cardiopulmonary exercise testing in obese and lean subjects.

\begin{tabular}{cccc}
\hline Peak & Obese $(\boldsymbol{n = 2 9 )}$ & Lean $(\boldsymbol{n}=\mathbf{2 9})$ & $p$-Value \\
\hline Oxygen uptake $(\mathrm{mL} / \mathrm{min})$ & $2070 \pm 422$ & $2219 \pm 546$ & 0.355 \\
Oxygen uptake $(\mathrm{mL} / \mathrm{min} / \mathrm{kg})$ & $23.9 \pm 4.8$ & $40.8 \pm 6.6$ & $<0.001$ \\
Carbon dioxide output $(\mathrm{mL} / \mathrm{min})$ & $2548 \pm 557$ & $2740 \pm 714$ & 0.265 \\
Minute ventilation $(\mathrm{L} / \mathrm{min})$ & $76 \pm 19$ & $83 \pm 23$ & 0.125 \\
Tidal volume $(\mathrm{L})$ & $1.90 \pm 0.46$ & $1.90 \pm 0.47$ & 0.994 \\
Breathing frequency (breaths/min) & $41 \pm 8$ & $45 \pm 9$ & 0.108 \\
Ventilatory equivalent $\mathrm{O}_{2}$ & $36.8 \pm 4.7$ & $37.7 \pm 5.8$ & 0.602 \\
Ventilatory equivalent CO & $30.5 \pm 3.5$ & 0.476 \\
Respiratory exchange ratio & $29.9 \pm 2.8$ & $1.23 \pm 0.07$ & 0.868 \\
Oxygen pulse $\left(\mathrm{mL} \mathrm{O}_{2} /\right.$ heart beat) & $1.23 \pm 0.07$ & $11.9 \pm 2.8$ & 0.305 \\
Work rate $(\mathrm{W})$ & $11.1 \pm 2.0$ & $189 \pm 44$ & 0.010 \\
Oxygen uptake/Work rate $(\mathrm{mL} / \mathrm{min} / \mathrm{W})$ & $161 \pm 35$ & $11.7 \pm 0.8$ & $<0.001$ \\
\hline
\end{tabular}


Table 3. Cont.

\begin{tabular}{cccc}
\hline Peak & Obese $(\boldsymbol{n}=\mathbf{2 9 )}$ & Lean $(\boldsymbol{n}=\mathbf{2 9})$ & $p$-Value \\
\hline Heart rate (bpm) & $185 \pm 11$ & $186 \pm 9$ & 0.843 \\
Mechanical efficiency (\%) & $21.3 \pm 1.9$ & $23.1 \pm 1.4$ & $<0.001$ \\
Net mechanical efficiency (\%) & $25.3 \pm 2.2$ & $27.1 \pm 2.2$ & 0.005 \\
Lipid oxidation (g/min) & $0.00 \pm 0.00$ & $0.00 \pm 0.00$ & 0.317 \\
Carbohydrate oxidation (g/min) & $4.74 \pm 1.21$ & $5.27 \pm 1.60$ & 0.167 \\
\hline
\end{tabular}

Data are expressed as mean \pm SD. Abbreviations: W: Watt, bpm: beats per minute. Comparisons between two groups were performed using the independent-samples t-test or Mann-Whitney U test.

\section{$\mathrm{VO}_{2} / \mathrm{WR}(\mathrm{ml} / \mathrm{min} / \mathrm{W})$}

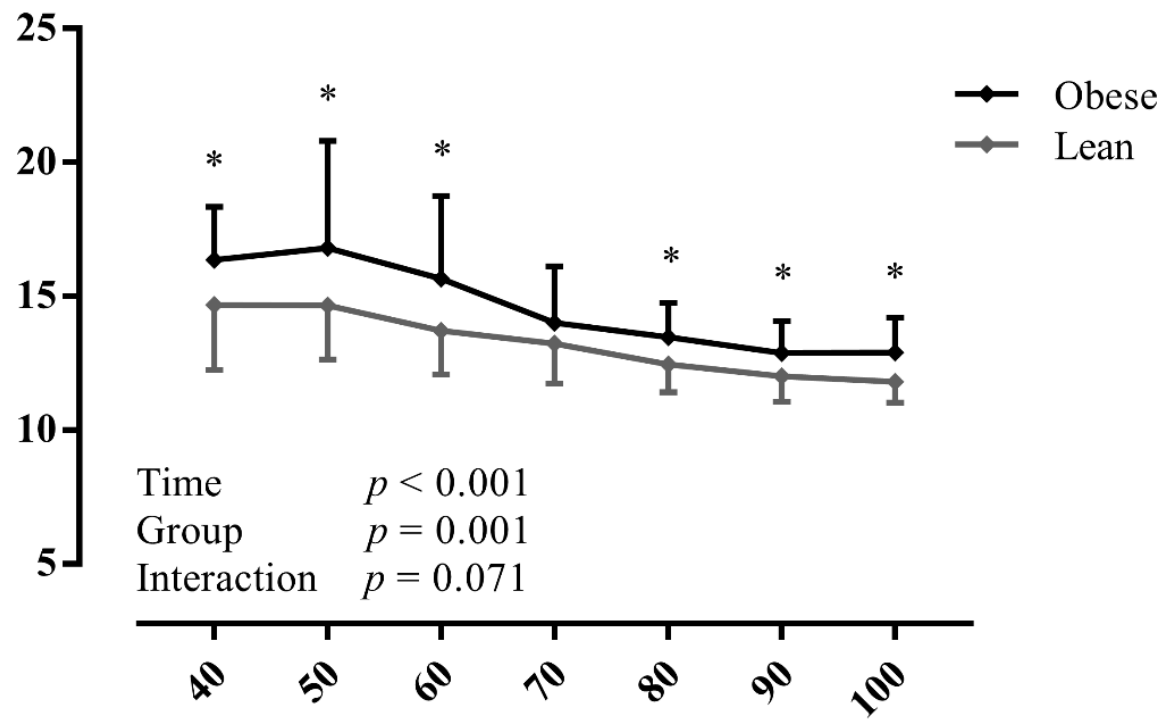

Figure 1. The oxygen uptake per work rate in relation to percentage of peak oxygen uptake in lean subjects and subjects with obesity during maximal exercise testing. Data are presented as mean $\pm \mathrm{SD}$. A two-way repeated-measures ANOVA (with post-hoc Bonferroni correction) was used to assess whether there were differences in mechanical efficiency during exercise testing between adolescents with obesity and lean adolescents. Abbreviations: $\dot{\mathrm{VO}}_{2} / \mathrm{WR}$ : oxygen uptake per work rate, W: Watt. * $p<0.05$ between groups.

\subsection{Associations between Mechanical Efficiency and Exercise Tolerance or Metabolic Health}

A higher $\mathrm{ME}_{\text {net }}$ at peak exercise was independently related (model $\left.\mathrm{r}^{2}=0.774 ; p<0.001\right)$ to a higher $\mathrm{WR}_{\text {peak }}(\mathrm{SC} \beta=2.447 ; p<0.001)$ and diminished $\mathrm{CHO}(\mathrm{SC} \beta=-0.497 ; p<0.001)$. With regard to metabolic health, a lowered $\mathrm{ME}_{\text {net }}$ was significantly and independently associated (model $\mathrm{r}^{2}=0.134 ; p=0.021$ ) with elevated blood LDL cholesterol (SC $\beta=-0.275$; $p=0.034$ ) and glucose (SC $\beta=-0.256 ; p=0.049$ ) concentrations. 
ME (\%)
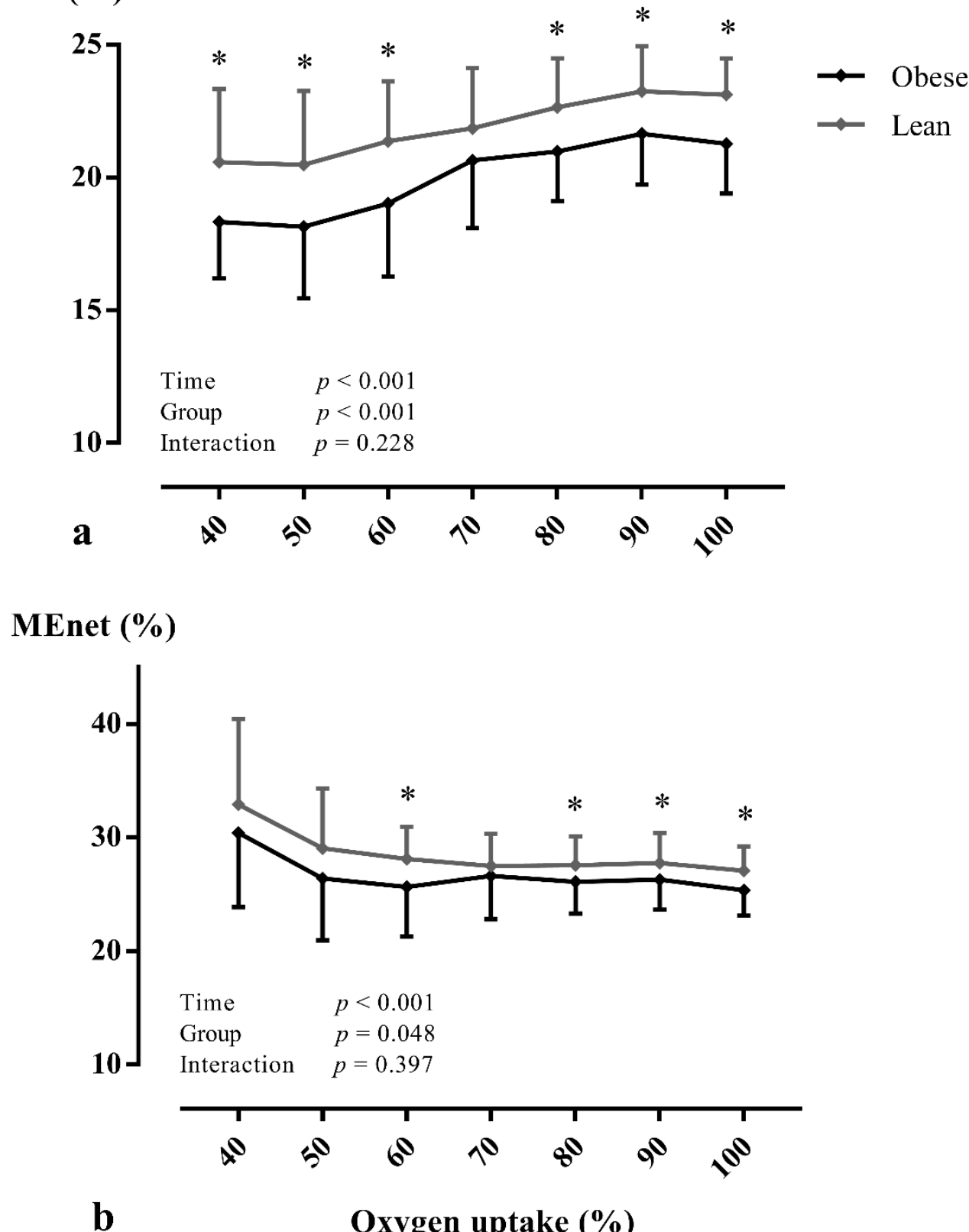

Figure 2. The mechanical efficiency (a) and net mechanical efficiency (b) in relation to percentage of peak oxygen uptake in lean subjects and subjects with obesity during maximal exercise testing. Data are presented as mean \pm SD. A two-way repeated-measures ANOVA (with post-hoc Bonferroni correction) was used to assess whether there were differences in mechanical efficiency during exercise testing between adolescents with obesity and lean adolescents. Abbreviations: ME: mechanical efficiency, MEnet: net mechanical efficiency. ${ }^{*} p<0.05$ between groups.

\section{Discussion}

In the present study, a decreased $\mathrm{ME}_{\text {net }}$ was present in adolescents with obesity. This is independently associated with a lowered $W_{\text {peak }}$, elevated blood LDL cholesterol, and fasting glucose concentrations. Data from the present study thus seem to verify that obesity, even at young age, is related to mechanical inefficiency during exercise, which relates to exercise intolerance and a worse metabolic health.

At rest, an increase in $\dot{\mathrm{V}} \mathrm{O}_{2}, \dot{\mathrm{V}} \mathrm{CO}_{2}$, and $\mathrm{HR}$ was found in adolescents with obesity. It has been shown that energy expenditure in children and adolescents with obesity increased at rest, possibly due to their increased fat free mass and sympathetic drive [28,29]. In 
addition, $\mathrm{WR}_{\text {peak }}$ was significantly reduced by $\sim 15 \%$ in adolescents with obesity, indicating that exercise intolerance is prevalent in this population. In a recent meta-analysis, it remained uncertain whether $W_{\text {peak }}$ would be reduced consistently in adolescents with obesity, although two out of three studies reported a reduced $W_{R_{\text {peak }}}$ [6]. This reduced $\mathrm{WR}_{\text {peak }}$ was observed in presence of a maintained $\dot{\mathrm{VO}}_{2 \text { peak }}$, thus indicating that the total oxygen uptake and transport is not the limiting factor during exercise in this population, but how oxygen is used in muscular metabolism.

A reduction in $W_{\text {peak }}$ may indeed result from exercise inefficiency of the skeletal muscles, as described previously in adults with obesity [30]. In line with these findings, data from the present study show significantly that $\mathrm{ME}$ (by $8 \%$ ) and $\mathrm{ME}_{\text {net }}$ (by $7 \%$ ) decreased, and that $\dot{\mathrm{VO}}_{2 \text { peak }} / \mathrm{WR}_{\text {peak }}$ (by $10 \%$ ) increased in adolescents with obesity, and an independent relation between a reduced $\mathrm{ME}_{\text {net }}$ and WRpeak (SC $\beta=2.447 ; p<0.001$ ). A reduced skeletal muscle work efficiency is hypothesized to be caused by metabolic muscle dysfunction [31] and/or a reduced mitochondrial content [32]. Moreover, the endocrine axes, including thyroid hormones and leptin, may play a role in the development of a decreased skeletal muscle ME [33,34]. These hormones affect the relative proportions of muscle fiber types [35], skeletal muscle glycolytic capacity, and alterations in the proportions of isoforms of the heavy chain of myosin (MHC) [33]. In addition, studies have shown that the skeletal muscles of adults with obesity are comprised of a lower proportion of oxidative type I skeletal muscle fibers [36]. This would lead to an attenuated skeletal muscle oxidative metabolism in individuals with obesity [31]. Although the relationship between muscle fiber type and obesity in adolescents has not been investigated, limited evidence of impaired exercise fat oxidation in pubertal boys with obesity was shown by Zunquin et al. [37]. Another explanation for deficits in skeletal muscle oxidative metabolism in individuals with obesity is a reduction in key enzymes associated with the oxidation of fats, leading to a reduced capacity for fatty acid oxidation in skeletal muscles [38]. Our results are in line with these previous findings, since significantly reduced lipid oxidation and increased carbohydrate oxidation were both noticed at rest in adolescents with obesity. In addition, this probably explains the independent association between a lower $\mathrm{ME}_{\text {net }}$ and a higher carbohydrate oxidation during CPET.

A lowered $\mathrm{ME}_{\text {net }}$ is independently associated with elevated blood LDL cholesterol (SC $\beta=-0.275 ; p=0.034$ ) and fasting glucose (SC $\beta=-0.256 ; p=0.049$ ) concentrations in adolescents with obesity. It thus follows that obese adolescents with mechanical inefficiency are more likely to display a disturbed blood lipid profile and higher fasting glucose levels. It has been shown that both high blood LDL cholesterol levels and fasting glucose concentration are associated with insulin resistance $[39,40]$. It may be hypothesized that insulin resistance relates to skeletal muscle mitochondrial dysfunction [41], and hence a reduced $M E_{\text {net }}$ and $\mathrm{WR}_{\text {peak }}$.

Data from the present study indicate that mechanical efficiency during exercise may be an important clinical parameter that deserves greater attention in adolescents with obesity. Moreover, since mechanical efficiency is linked to metabolic health and exercise tolerance, it may be hypothesized that exercise intervention/therapy should be offered to every adolescent with obesity with the aim to normalize the mechanical efficiency during exercise [9]. As a result, it is expected that a higher ME will improve metabolic health.

\section{Limitations and Future Directions}

This is the first study that relates mechanical inefficiency during CPET to a worse metabolic health and exercise intolerance in adolescents with obesity. Despite these innovative findings, there are several limitations of this study. The primary limitation of this study is the cross-sectional design which does not allow the examination of causality. Therefore, data obtained from prospective studies with training and detraining effects are recommended to confirm our findings. We classified groups with obesity based on BMI without using a valid and reliable measure of body composition. In future research, it 
is recommended to characterize different subjects by body composition measured using dual-energy $\mathrm{x}$-ray absorptiometry or MRI.

\section{Conclusions}

This study demonstrates that, in adolescents with obesity, ME during exercise is significantly impaired, which relates to exercise intolerance and elevated blood LDL cholesterol and glucose concentrations. Therefore, ME could be used as an important parameter evaluating (cardio)metabolic health.

Supplementary Materials: The following are available online at https:/ /www.mdpi.com/article/10 .3390/ijerph182010578/s1, Table S1: Subject characteristics of obese and lean individuals, Table S2: Biochemical and hormonal parameters in obese and lean adolescents, Table S3: Cardiopulmonary function in rest, at VT1 and VT2 during cardiopulmonary exercise testing in obese and lean subjects, Figure S1: Sex differences of the oxygen uptake per work rate in relation to percentage of peak oxygen uptake in lean subjects and subjects with obesity during with maximal exercise testing, Figure S2: Sex differences of the mechanical efficiency.

Author Contributions: W.M.A.F. drafted the initial manuscript, included the participants, performed the measurements, carried out the initial analyses and revised the manuscript. K.V. included the participants, performed the measurements, carried out the initial analysis and critically reviewed the manuscript. B.O.E. and P.D. conceptualized and designed the study and critically reviewed the manuscript. G.M. and D.H. conceptualized and designed the manuscript, drafted the initial manuscript, included the participants and carried out the initial analyses. All authors have read and agreed to the published version of the manuscript.

Funding: This research received no external funding and was supported by internal resources from Hasselt University.

Institutional Review Board Statement: The study was conducted according to the guidelines of the Declaration of Helsinki, and approved by the Ethics Committee of Jessa Hospital and Hasselt University (protocol code: B243201214935, date of approval: 23 November 2016).

Informed Consent Statement: Informed consent was obtained from all subjects involved in the study.

Data Availability Statement: Data available on request due to restrictions (e.g. privacy or ethical).

Acknowledgments: We would like to thank all adolescents for their participation and guidance of their parents during this study. Furthermore, we thank the clinicians from the department of pediatrics at the Jessa Hospital for all the support in this study.

Conflicts of Interest: D. Hansen discloses receiving personal remuneration for consultancy and/or lectures from Johnson \& Johnson outside the scope of this work. All other authors declared that they had no conflict of interest.

\section{References}

1. Abarca-Gómez, L.; Abdeen, Z.A.; Hamid, Z.A.; Abu-Rmeileh, N.M.; Acosta-Cazares, B.; Acuin, C. Worldwide trends in body-mass index, underweight, overweight, and obesity from 1975 to 2016: A pooled analysis of 2416 population-based measurement studies in 1289 million children, adolescents, and adults. Lancet 2017, 390, 2627-2642. [CrossRef]

2. Bays, H. Adiposopathy, "sick fat," Ockham's razor, and resolution of the obesity paradox. Curr. Atheroscler. Rep. 2014, 16, 409. [CrossRef]

3. Neef, M.; Weise, S.; Adler, M.; Sergeyev, E.; Dittrich, K.; Korner, A.; Kiess, W. Health impact in children and adolescents. Best Pract. Res. Clin. Endocrinol. Metab. 2013, 27, 229-238. [CrossRef] [PubMed]

4. Finkelstein, E.A.; Graham, W.C.K.; Malhotra, R. Lifetime direct medical costs of childhood obesity. Pediatrics 2014, 133, 854-862. [CrossRef] [PubMed]

5. $\quad$ Franssen, W.M.A.; Beyens, M.; Hatawe, T.A.; Frederix, I.; Verboven, K.; Dendale, P.; Hansen, D. Cardiac function in adolescents with obesity: Cardiometabolic risk factors and impact on physical fitness. Int. J. Obes. 2019, 43, 1400-1410. [CrossRef]

6. Hansen, D.; Marinus, N.; Remans, M.; Courtois, I.; Cools, F.; Calsius, J.; Massa, G.; Takken, T. Exercise tolerance in obese vs. lean adolescents: A systematic review and meta-analysis. Obes. Rev. Off. J. Int. Assoc. Study Obes. 2014, 15, 894-904. [CrossRef]

7. Jabbour, G.; Lambert, M.; O'Loughlin, J.; Tremblay, A.; Mathieu, M.E. Mechanical efficiency during a cycling test is not lower in children with excess body weight and low aerobic fitness. Obesity 2013, 21, 107-114. [CrossRef] 
8. Jabbour, G.; Majed, L. Mechanical Efficiency at Different Exercise Intensities Among Adolescent Boys with Different Body Fat Levels. Front. Physiol. 2019, 10, 265. [CrossRef]

9. Jabbour, G.; Iancu, H.D. Mechanical efficiency improvement in relation to metabolic changes in sedentary obese adults. BMJ Open Sport Exerc. Med. 2015, 1, e000044. [CrossRef]

10. Villelabeitia-Jaureguizar, K.; Vicente-Campos, D.; Berenguel Senen, A.; Hernandez Jimenez, V.; Ruiz Bautista, L.; Barrios GarridoLestache, M.E.B.; Chicharro, J.L. Mechanical efficiency of high versus moderate intensity aerobic exercise in coronary heart disease patients: A randomized clinical trial. Cardiol. J. 2019, 26, 130-137. [CrossRef] [PubMed]

11. Ettema, G.; Loras, H.W. Efficiency in cycling: A review. Eur. J. Appl. Physiol. 2009, 106, 1-14. [CrossRef]

12. Lafortuna, C.L.; Proietti, M.; Agosti, F.; Sartorio, A. The energy cost of cycling in young obese women. Eur. J. Appl. Physiol. 2006, 97, 16-25. [CrossRef] [PubMed]

13. Silva, G.; Aires, L.; Martins, C.; Mota, J.; Oliveira, J.; Ribeiro, J.C. Cardiorespiratory fitness associates with metabolic risk independent of central adiposity. Int. J. Sports Med. 2013, 34, 912-916. [CrossRef] [PubMed]

14. Waldburger, R.; Wilms, B.; Ernst, B.; Thurnheer, M.; Schultes, B. Cardio-respiratory fitness is independently associated with cardio-metabolic risk markers in severely obese women. Exp. Clin. Endocrinol. Diabetes Off. J. Ger. Soc. Endocrinol. Ger. Diabetes Assoc. 2014, 122, 190-194. [CrossRef] [PubMed]

15. Diez-Fernandez, A.; Sanchez-Lopez, M.; Mora-Rodriguez, R.; Notario-Pacheco, B.; Torrijos-Nino, C.; Martinez-Vizcaino, V. Obesity as a mediator of the influence of cardiorespiratory fitness on cardiometabolic risk: A mediation analysis. Diabetes Care 2014, 37, 855-862. [CrossRef] [PubMed]

16. Cole, T.J.; Lobstein, T. Extended international (IOTF) body mass index cut-offs for thinness, overweight and obesity. Pediatric Obes. 2012, 7, 284-294. [CrossRef] [PubMed]

17. McCarthy, H.D.; Cole, T.J.; Fry, T.; Jebb, S.A.; Prentice, A.M. Body fat reference curves for children. Int. J. Obes. 2006, 30, 598-602. [CrossRef]

18. Cole, T.J.; Green, P.J. Smoothing reference centile curves: The LMS method and penalized likelihood. Stat. Med. 1992, 11, 1305-1319. [CrossRef] [PubMed]

19. Rodríguez, G.; Moreno, L.A.; Blay, M.G.; Blay, V.A.; Fleta, J.; Sarría, A.; Bueno, M. Body fat measurement in adolescents: Comparison of skinfold thickness equations with dual-energy X-ray absorptiometry. Eur. J. Clin. Nutr. 2005, 59, 1158-1166. [CrossRef]

20. Slaughter, M.H.; Lohman, T.G.; Boileau, R.A.; Horswill, C.A.; Stillman, R.J.; Van Loan, M.D.; Bemben, D.A. Skinfold equations for estimation of body fatness in children and youth. Hum. Biol. 1988, 60, 709-723.

21. Matthews, D.R.; Hosker, J.P.; Rudenski, A.S.; Naylor, B.A.; Treacher, D.F.; Turner, R.C. Homeostasis model assessment: Insulin resistance and beta-cell function from fasting plasma glucose and insulin concentrations in man. Diabetologia 1985, 28, 412-419. [CrossRef]

22. Bongers, B.C.; Hulzebos, E.H.; Helbing, W.A.; Ten Harkel, A.; van Brussel, M.; Takken, T. Response profiles of oxygen uptake efficiency during exercise in healthy children. Eur. J. Prev. Cardiol. 2016, 23, 865-873. [CrossRef]

23. Salvadori, A.; Fanari, P.; Giacomotti, E.; Palmulli, P.; Bolla, G.; Tovaglieri, I.; Luzi, L.; Longhini, E. Kinetics of catecholamines and potassium, and heart rate during exercise testing in obese subjects. Heart rate regulation in obesity during exercise. Eur. J. Nutr. 2003, 42, 181-187. [CrossRef] [PubMed]

24. Wasserman, K.; Stringer, W.W.; Casaburi, R.; Koike, A.; Cooper, C.B. Determination of the anaerobic threshold by gas exchange: Biochemical considerations, methodology and physiological effects. Z. Kardiol. 1994, 83 (Suppl. 3), 1-12.

25. Beaver, W.L.; Wasserman, K.; Whipp, B.J. A new method for detecting anaerobic threshold by gas exchange. J. Appl. Physiol. 1986, 60, 2020-2027. [CrossRef] [PubMed]

26. Garby, L.; Astrup, A. The relationship between the respiratory quotient and the energy equivalent of oxygen during simultaneous glucose and lipid oxidation and lipogenesis. Acta Physiol. Scand. 1987, 129, 443-444. [CrossRef] [PubMed]

27. Frayn, K.N. Calculation of substrate oxidation rates in vivo from gaseous exchange. J. Appl. Physiol. Respir. Environ. Exerc. Physiol. 1983, 55, 628-634. [CrossRef] [PubMed]

28. Marinus, N.; Bervoets, L.; Massa, G.; Verboven, K.; Stevens, A.; Takken, T.; Hansen, D. Altered gas-exchange at peak exercise in obese adolescents: Implications for verification of effort during cardiopulmonary exercise testing. J. Sports Med. Phys. Fit. 2017, 57, 1687-1694.

29. Rodriguez, G.; Moreno, L.A.; Sarria, A.; Pineda, I.; Fleta, J.; Perez-Gonzalez, J.M.; Bueno, M. Determinants of resting energy expenditure in obese and non-obese children and adolescents. J. Physiol. Biochem. 2002, 58, 9-15. [CrossRef] [PubMed]

30. Goldsmith, R.; Joanisse, D.R.; Gallagher, D.; Pavlovich, K.; Shamoon, E.; Leibel, R.L.; Rosenbaum, M. Effects of experimental weight perturbation on skeletal muscle work efficiency, fuel utilization, and biochemistry in human subjects. Am. J. Physiol. Regul. Integr. Comp. Physiol. 2010, 298, R79-R88. [CrossRef]

31. Wells, G.D.; Noseworthy, M.D.; Hamilton, J.; Tarnopolski, M.; Tein, I. Skeletal muscle metabolic dysfunction in obesity and metabolic syndrome. Can. J. Neurol. Sci. Le J. Can. Des Sci. Neurol. 2008, 35, 31-40. [CrossRef] [PubMed]

32. Roden, M. Muscle triglycerides and mitochondrial function: Possible mechanisms for the development of type 2 diabetes. Int. J. Obes. 2005, 29 (Suppl. 2), S111-S115. [CrossRef] [PubMed]

33. Caiozzo, V.J.; Baker, M.J.; Baldwin, K.M. Novel transitions in MHC isoforms: Separate and combined effects of thyroid hormone and mechanical unloading. J. Appl. Physiol. 1998, 85, 2237-2248. [CrossRef] [PubMed] 
34. Reinehr, T.; Isa, A.; de Sousa, G.; Dieffenbach, R.; Andler, W. Thyroid hormones and their relation to weight status. Horm. Res. 2008, 70, 51-57. [CrossRef]

35. Everitt, A.V.; Terry, V.; Phillips, M.J.; Kerry, H.M.; Shorey, C.D. Morphometric analysis of gastrocnemius muscle fiber size and fiber proportions in the hypophysectomized rat after prolonged administration of growth hormone or thyroxine. Growth Dev. Aging 1996, 60, 85-93.

36. Tanner, C.J.; Barakat, H.A.; Dohm, G.L.; Pories, W.J.; MacDonald, K.G.; Cunningham, P.R.; Swanson, M.S.; Houmard, J.A. Muscle fiber type is associated with obesity and weight loss. Am. J. Physiol. Endocrinol. Metab. 2002, 282, E1191-E1196. [CrossRef]

37. Zunquin, G.; Theunynck, D.; Sesboue, B.; Arhan, P.; Bougle, D. Comparison of fat oxidation during exercise in lean and obese pubertal boys: Clinical implications. Br. J. Sports Med. 2009, 43, 869-870. [CrossRef]

38. Houmard, J.A.; Pories, W.J.; Dohm, G.L. Severe obesity: Evidence for a deranged metabolic program in skeletal muscle? Exerc. Sport Sci. Rev. 2012, 40, 204-210. [CrossRef]

39. Steinberger, J.; Moorehead, C.; Katch, V.; Rocchini, A.P. Relationship between insulin resistance and abnormal lipid profile in obese adolescents. J. Pediatrics 1995, 126, 690-695. [CrossRef]

40. Ahren, B. Insulin secretion and insulin sensitivity in relation to fasting glucose in healthy subjects. Diabetes Care 2007, 30, 644-648. [CrossRef]

41. Ye, J. Mechanisms of insulin resistance in obesity. Front. Med. 2013, 7, 14-24. [CrossRef] 